\title{
EFEITO DO SORO DO LEITE E GOMA GUAR NOS TEORES DE LACTOSE, ÁCIDO LÁTICO E TEMPO DE FERMENTAÇÃO DE BEBIDAS LÁCTEAS
}

\author{
SHANA PIRES FERREIRA* \\ MARTA HEIDTMANN GONÇALVES** \\ WILLIAN JOSE VARELA*** \\ PATRICIA PINHEIRO DOS SANTOS ACOSTA**** \\ WALTER AUGUSTO RUIZ***** \\ MARTA MARIA MARQUEZAN AUGUSTO******
}

\begin{abstract}
Visando melhor aproveitamento do soro de queijo estudou-se a influência da proporção de soro e da concentração de hidrocoloide nos teores de lactose, ácido lático e tempo de fermentação de bebidas lácteas. Utilizou-se planejamento composto central rotacional com 3 pontos centrais, totalizando 11 experimentos. Empregaram-se as proporções soro/leite de 51, 55, 65, 75 e $79 \%$, e as concentrações de hidrocoloide de 0,$03 ; 0,04 ; 0,07 ; 0,10$ e $0,11 \%$. Os resultados foram tratados por análise de variância ao nível de significância de $5 \%$. A proporção de soro influenciou significativamente $(p<0,05)$ as variáveis resposta tempo de fermentação, lactose, sólidos totais e acidez titulável, porém não houve influência significativa $(p<0,05)$ para a concentração de hidrocoloide. Menores tempos de fermentação foram atingidos quando se utilizou até $65 \%$ de soro. Os maiores teores de lactose foram obtidos nos experimentos com maior proporção de soro, enquanto que as bebidas com menor proporção de soro apresentaram maior teor de sólidos totais e acidez titulável.
\end{abstract}

* Engenheira de Alimentos, Doutoranda em Engenharia e Ciência de Alimentos, Universidade Federal do Rio Grande (FURG), Rio Grande, RS (e-mail: shanaferreira@gmail.com).

** Engenheira de Alimentos, Mestre em Engenharia e Ciência de Alimentos, FURG, Rio Grande, RS (e-mail: martinhahp@yahoo.com.br).

*** Engenheiro de Alimentos, Mestre em Ciência e Tecnologia de Alimentos, Universidade Federal do Rio Grande do Sul (UFRGS), Porto Alegre, RS (e-mail: willian.varela@gmail.com).

**** Engenheira de Alimentos, FURG, Rio Grande, RS (e-mail: patri11@bol.com.br).

***** Químico, Doutor em Ciência de Alimentos, Docente, Escola de Química e Alimentos, FURG, Rio Grande, RS (e-mail: dqmwar@furg.br).

******Química, Doutora em Tecnologia de Alimentos, Docente, Escola de Química e Alimentos, FURG, Rio Grande, RS (e-mail: dqmmarta@furg.br). 


\section{INTRODUÇÃO}

O consumo de bebidas lácteas fermentadas vem aumentando sensivelmente no Brasil, provavelmente devido às suas propriedades sensoriais e nutricionais (ALMEIDA, BONASSI e ROÇA, 2001). De acordo com a legislação brasileira, as bebidas lácteas fermentadas são elaboradas com leite, soro de queijo, aromatizantes, corantes, edulcorantes, polpa de frutas e outros insumos (SIVIERI e OLIVEIRA, 2002).

O soro do leite, subproduto da fabricação do queijo, representa entre 80 a $90 \%$ do volume do leite processado e pode conter até $55 \%$ do total dos sólidos do leite, sendo denominado de soro doce quando a maior fração de sólidos é constituída por lactose (PORTO, SANTOS e MIRANDA, 2005; ANDRADE e MARTINS, 2002). O soro também pode ser obtido por precipitação ácida, sendo denominado soro ácido. Os tipos de soro resultantes desses processos apresentam composições diferentes (PELEGRINE e CARRASQUEIRA, 2008). O soro doce apresenta $4,9 \%$ de lactose, $0,9 \%$ de proteína bruta, $1,03 \%$ de gordura, $0,5 \%$ de cinzas, $6,7 \%$ de sólidos totais e $\mathrm{pH} 6,2$. Já o soro ácido é composto por $4,3 \%$ de lactose, $0,9 \%$ de proteína bruta, $0,48 \%$ de gordura, $0,8 \%$ de cinzas, $6,4 \%$ de sólidos totais e pH 4,6 (SILVA, BOLINI e ANTUNES, 2004). A utilização do soro de queijo na elaboração de bebidas lácteas representa forma racional de aproveitamento desse produto, que além de apresentar excelente valor nutritivo, fornece alta qualidade proteica com baixo teor de gordura e lactose (SMITH, 2003; ALMEIDA, BONASSI e ROÇA, 2001).

O soro apresenta inúmeras aplicações nas indústrias de lácteos, carnes, panificação, chocolate, bebidas e outras. Os hidrocoloides ou coloides hidrofílicos, como as gomas, são importantes componentes da textura dos alimentos devido às suas propriedades que possibilitam a estabilização de emulsões de óleo em água (GARCIA-CRUZ, 2001), podendo agir como agentes emulsificantes (DICKINSON, 2009). Os hidrocoloides são utilizados como insumos na elaboração de bebidas carbonatadas (TAN, 2004), sorvetes, molhos, temperos (SIKORA et al., 2008), pudins e sobremesas (MUNHOZ, WEBER e CHANG, 2004).

A goma guar, galactomanana neutra, extraída da Cyamopsis tetragonolobus contém manose e galactose na proporção de 2:1. É estável ao calor e capaz de formar dispersões coloidais em água com elevada viscosidade. Galactomananas, como goma guar e a goma da planta do feijão, são amplamente utilizadas na indústria alimentícia como espessantes e agentes estabilizantes (DICKINSON, 2003), principalmente na elaboração de produtos lácteos (como iogurte e sorvete) contribuindo para a diminuição da sinérese (MUNHOZ, WEBER e CHANG, 2004).

Processos de fermentação utilizando micro-organismos, enzimas e processos mistos, resultam em produto que pode enobrecer a matéria-prima, deixando-a apta para o consumo (SPREER, 1991), além de contribuir para o aumento do valor nutricional dos alimentos (BICUDO et al., 2012). No processo de fermentação láctica são utilizadas culturas lácteas constituídas por Streptococcus thermophilus e Lactobacillus delbruecki subs. bulgaricus que são micro-organismos com metabolismo estritamente fermentativo, apresentando o ácido láctico como principal produto da fermentação de carboidratos (MARTINIS, ALVES e FRANCO, 2002). As culturas podem, eventualmente, incluir Streptococcus lactis e diacetilactis e Lactobacillus helveticus. Espécies de lactobacilos e estreptococos distinguem-se pela alta atividade em produzir ácido láctico e também pela atividade proteolítica (SALADO e ANDRADE, 1989).

O objetivo deste trabalho foi verificar o efeito da adição de soro e da concentração de hidrocoloide na elaboração de bebidas lácteas fermentadas.

\section{MATERIAL E MÉTODOS}

\subsection{MATÉRIA-PRIMA E INSUMOS}

Foram utilizados para a elaboração das bebidas lácteas fermentadas: leite pasteurizado padronizado, soro doce, sacarose (açúcar refinado), goma guar (Doce Aroma), polpa de fruta sabor 
morango (Ritter- $\mathrm{R}^{\circledR}$ ), cultura láctica termofílica contendo Streptococcus thermophilus e Lactobacillus delbrueckii subsp. bulgaricus (Yo-Mix 401- Danisco).

\subsection{PROCESSO PARA ELABORAÇÃO DE BEBIDAS LÁCTEAS FERMENTADAS}

As bebidas foram elaboradas em reatores de aço inox, com capacidade de $2 \mathrm{~L}$ e banho termostatizado com circulação de água. O processo consistiu em misturar o leite e o soro, aquecer a mistura a $70^{\circ} \mathrm{C}$, adicionar a sacarose e a goma guar. Realizou-se a pasteurização a $80^{\circ} \mathrm{C}$ por 15 minutos, seguida de resfriamento até a temperatura de $42^{\circ} \mathrm{C}$. Inoculou-se a cultura láctica $(5 / 1000(\mathrm{U} / \mathrm{L}))$ e procedeu-se a fermentação até $\mathrm{pH} 4,6$. A quebra do gel foi efetuada mediante agitação mecânica e resfriamento até a temperatura de $28^{\circ} \mathrm{C}$. Adicionou-se a polpa de fruta, sendo efetuada a homogeneização com resfriamento até $15^{\circ} \mathrm{C}$. $\mathrm{O}$ acondicionamento foi realizado em garrafas plásticas de $1 \mathrm{~L}$ e o armazenamento em câmara frigorífica a $5^{\circ} \mathrm{C}$. A formulação utilizada na elaboração da bebida láctea fermentada foi determinada conforme planejamento experimental (Tabela 1), sendo a concentração de sacarose e de polpa de fruta fixada em $4 \%$ e $0,8 \%$, respectivamente.

\subsection{CARACTERIZAÇÃO QUÍMICA DO LEITE E DO SORO}

As amostras de leite e soro foram caracterizadas quanto ao teor de gordura (\%), $\mathrm{pH}$, acidez titulável ( $\left.{ }^{\circ} \mathrm{D}\right)$, proteínas $(\%)$, resíduo mineral fixo (\%), sólidos totais $(\%)$, umidade (\%) e lactose (\%).

O teor de gordura foi determinado conforme o método de extração etéreo de Mojonnie, método n 989.05 da AOAC (2000) e o pH medido em potenciômetro digital (Quimis Q400HM, Brasil). A acidez titulável foi determinada por volumetria e expressa em graus Dornic ( $\left.{ }^{\circ} \mathrm{D}\right)$ (BRASIL, 2006). Determinou-se o teor de proteína pelo nitrogênio total (Kjeldahl), utilizando o fator de conversão de 6,38 (BRASIL, 2006). A determinação do resíduo mineral fixo foi realizada pelo método gravimétrico, em mufla, à temperatura de aproximadamente $550^{\circ} \mathrm{C}$ (BRASIL, 2006). Os sólidos totais foram determinados por método gravimétrico e o teor de lactose pelo método volumétrico de Lane-Eynon (BRASIL, 2006).

\subsection{PLANEJAMENTO EXPERIMENTAL E TRATAMENTO DOS RESULTADOS}

Adotou-se delineamento composto central rotacional (DCCR), com 2 variáveis em 2 níveis, 4 pontos axiais e 3 repetições no ponto central (BARROS NETO, SCARMINIO E BRUNS, 2010), totalizando 11 ensaios $\left(2^{2}+4+3\right)$. Os níveis das variáveis codificadas do planejamento experimental para a bebida láctea fermentada são apresentados na Tabela 1.

\section{TABELA 1 - NÍVEIS DE VARIÁVEIS CODIFICADAS DO PLANEJAMENTO EXPERIMENTAL PARA A BEBIDA LÁCTEA FERMENTADA}

\begin{tabular}{|c|c|c|c|c|c|}
\hline $\begin{array}{l}\text { Variável } \\
\text { codificada }\end{array}$ & $\begin{array}{c}-\alpha \\
(-1,41421)\end{array}$ & $\begin{array}{c}\text { Nível inferior } \\
(-1)\end{array}$ & $\begin{array}{l}\text { Ponto } \\
\text { central } \\
(0)\end{array}$ & $\begin{array}{c}\text { Nível } \\
\text { superior } \\
(+1)\end{array}$ & $\begin{array}{c}+\alpha \\
(+1,41421)\end{array}$ \\
\hline $\mathrm{X} 1$ & 51 & 55 & 65 & 75 & 79 \\
\hline $\mathrm{X} 2$ & 0,03 & 0,04 & 0,07 & 0,10 & 0,11 \\
\hline
\end{tabular}

$\mathrm{X} 1$ = porcentagem de soro; $\mathrm{X} 2$ = porcentagem de goma guar.

As variáveis resposta foram: tempo de fermentação (min), lactose (\%), sólidos totais (\%) e acidez titulável ( $\left.{ }^{\circ} \mathrm{D}\right)$. A Tabela 2 apresenta a matriz das variáveis codificadas e reais do planejamento experimental. 
TABELA 2 - MATRIZ DE PLANEJAMENTO COM AS VARIÁVEIS CODIFICADAS E REAIS PARA ELABORAÇÃO DAS BEBIDAS LÁCTEAS

\begin{tabular}{ccccc}
\hline & \multicolumn{2}{c}{ Variáveis codificadas } & \multicolumn{2}{c}{ Variáveis reais } \\
\cline { 2 - 5 } Experimento & \multicolumn{2}{c}{ X2 } & soro $(\%)$ & goma guar $(\%)$ \\
& \multicolumn{1}{c}{ X1 } & -1 & 55 & 0,04 \\
\hline 1 & -1 & -1 & 75 & 0,04 \\
2 & +1 & +1 & 55 & 0,10 \\
3 & -1 & +1 & 75 & 0,10 \\
4 & +1 & 0 & 51 & 0,07 \\
5 & $-\alpha(-1,41421)$ & 0 & 79 & 0,07 \\
6 & $+\alpha(+1,41421)$ & $-\alpha(-1,41421)$ & 65 & 0,03 \\
7 & 0 & $+\alpha(+1,41421)$ & 65 & 0,11 \\
8 & 0 & 0 & 65 & 0,07 \\
9 & 0 & 0 & 65 & 0,07 \\
10 & 0 & 0 & 65 & 0,07 \\
11 & 0 & & & \\
\hline
\end{tabular}

Os resultados foram tratados por análise de variância (ANOVA) ao nível de significância de $5 \%$, com o auxílio do programa Statistica ${ }^{\circledR}$ versão 5.0 (STATSOFT, 1995).

\section{RESULTADOS E DISCUSSÃO}

\subsection{COMPOSIÇÃO QUÍMICA DO LEITE E DO SORO}

O leite e o soro utilizados na elaboração das bebidas lácteas (Tabela 3) apresentaram composição química similar à do soro de queijo prato reportada por Spadoti et al. (2003) e atenderam a Instrução Normativa $n^{\circ} 51$ (BRASIL, 2002) quanto à qualidade exigida para a elaboração de produtos alimentícios.

\section{TABELA 3 - COMPOSIÇÃO PORCENTUAL MÉDIA DO LEITE E DO SORO UTILIZADOS NA ELABORAÇÃO DAS BEBIDAS LÁCTEAS FERMENTADAS}

\begin{tabular}{ccc}
\hline Determinações & Leite $(\mu \pm \sigma)$ & Soro $(\boldsymbol{\mu} \pm \sigma)$ \\
\hline Umidade & $88,30 \pm 0,27$ & $93,15 \pm 1,06$ \\
Sólidos totais & $11,70 \pm 0,27$ & $6,85 \pm 1,06$ \\
Proteína* & $3,12 \pm 0,04$ & $0,77 \pm 0,03$ \\
Resíduo mineral fixo & $0,70 \pm 0,04$ & $0,44 \pm 0,04$ \\
Gordura & $3,42 \pm 0,18$ & $0,56 \pm 0,04$ \\
Lactose & $4,45 \pm 0,01$ & $5,54 \pm 0,29$ \\
Acidez titulável ('D) & $18,64 \pm 0,01$ & $12,20 \pm 0,01$ \\
pH & $6,72 \pm 0,06$ & $6,44 \pm 0,17$ \\
\hline
\end{tabular}

* \% Proteína = \%NT x 6,38; $(\mu \pm \sigma)$ média \pm desvio padrão $(n=4)$.

\subsection{INFLUÊNCIA DA CONCENTRAÇÃO DE SORO E DE GOMA GUAR NA ELABORAÇÃO DAS BEBIDAS LÁCTEAS FERMENTADAS}

Os resultados experimentais mostrados na Tabela 4 demonstram que o tempo de fermentação constitui fator importante na elaboração da bebida láctea fermentada. As bebidas com as maiores proporções de soro apresentaram maior teor de lactose (Tabela 4), resultado que pode 
ser associado à maior concentração de lactose no soro do que no leite. Os teores de sólidos totais e a acidez titulável mostraram tendência de redução (Tabela 4).

As mudanças que ocorrem nos constituintes do leite (principalmente proteínas, gorduras e vitaminas) durante a fermentação (SALADO e ANDRADE, 1989) exercem influência nas propriedades sensoriais e dietéticas do produto final. Bebidas lácteas com maior proporção de leite (que apresenta maior teor proteico e de gorduras que o soro) exigem menor tempo de fermentação, já que esses nutrientes auxiliam o metabolismo microbiano, acelerando a fermentação.

\section{TABELA 4 - TEORES DE LACTOSE, SÓLIDOS TOTAIS E ACIDEZ TITULÁVEL NO FINAL DA FERMENTAÇÃO}

\begin{tabular}{ccccccc}
\hline Experimento & $\mathbf{X 1}$ & $\mathbf{X 2}$ & $\begin{array}{c}\text { Tempo } \\
(\mathbf{m i n})\end{array}$ & $\begin{array}{c}\text { Lactose } \\
\mathbf{( \% )}\end{array}$ & $\begin{array}{c}\text { Sólidos } \\
\text { totais (\%) }\end{array}$ & $\begin{array}{c}\text { Ac. titulável } \\
\text { ('D) }\end{array}$ \\
\hline 1 & 55 & 0,04 & 270 & 4,51 & 12,28 & 52,64 \\
2 & 75 & 0,04 & 360 & 5,45 & 9,98 & 48,68 \\
3 & 55 & 0,10 & 270 & 4,69 & 12,57 & 51,92 \\
4 & 75 & 0,10 & 360 & 5,39 & 9,74 & 47,95 \\
5 & 51 & 0,07 & 270 & 4,62 & 13,48 & 55,07 \\
6 & 79 & 0,07 & 360 & 5,40 & 8,69 & 48,38 \\
7 & 65 & 0,03 & 270 & 5,11 & 11,32 & 49,70 \\
8 & 65 & 0,11 & 300 & 5,14 & 12,14 & 50,13 \\
9 & 65 & 0,07 & 270 & 5,10 & 12,00 & 49,35 \\
10 & 65 & 0,07 & 270 & 5,19 & 11,80 & 49,69 \\
11 & 65 & 0,07 & 270 & 5,16 & 11,72 & 49,03 \\
\hline
\end{tabular}

$\mathrm{X} 1=$ soro $(\%) ; \mathrm{X} 2$ = hidrocoloide $(\%)$.

Ferrreira et al. (2005), estudando a influência de diferentes proporções de soro no tempo de fermentação de bebidas lácteas, observaram diminuição mais lenta do $\mathrm{pH}$ em bebidas com maior proporção de soro durante as primeiras horas do processo de fermentação.

Os efeitos estimados no tempo de fermentação, nos teores de lactose, sólidos totais e na acidez titulável podem ser verificados na Figura 1 , notando-se a influência significativa $(p<0,05)$ do soro tanto no modelo linear como no modelo quadrático.

A análise de variância (ANOVA, Tabela 5) do tempo de fermentação permite verificar que o modelo codificado não é estatisticamente significativo nem preditivo, pois o modelo teórico para ser considerado significativo deve apresentar valor de $\mathrm{F}$ calculado $\left(\mathrm{F}_{\text {calc }}\right)$ superior a pelo menos três vezes o valor de $F$ tabelado $\left(F_{\text {tab }}\right)$. Por esse motivo não foi apresentada a equação codificada do modelo nem a superfície de resposta.

TABELA 5 - ANOVA DOS RESULTADOS DO TEMPO DE FERMENTAÇÃO

\begin{tabular}{cccccc}
\hline F.V & $\mathbf{S . Q}$ & $\mathbf{G . L}$ & $\mathbf{M . Q}$ & $\mathbf{F}_{\text {calc }}$ & $\mathbf{F}_{\text {tab }}$ \\
\hline Regressão & 14577,578 & 5 & 2915,52 & 8,99 & 5,05 \\
Resíduo & 1622,422 & 5 & 324,48 & & \\
Total & 16200 & 10 & & & \\
\hline
\end{tabular}

F.V = fonte de variação; $S . Q$ = soma quadrática; $G . L$ = graus de liberdade; $M . Q:$ = média quadrática; Coeficiente de determinação $R^{2}=0,8998 ; \%$ de variância explicada $=89,98 \%$.

$\mathrm{Na}$ análise de variância (ANOVA) para a variável resposta lactose (Tabela 6) é possível 
perceber que o valor de $\mathrm{F}_{\text {cal }}$ é 4,15 vezes superior ao valor de $\mathrm{F}_{\text {tab }}$. Além disso, apresenta coeficiente de determinação $\left(R^{2}\right)$ igual a 0,9545 . Assim sendo, o modelo codificado pode ser dito estatisticamente preditivo e significativo.

TABELA 6 - ANOVA DOS RESULTADOS DO TEOR DE LACTOSE

\begin{tabular}{cccccc}
\hline F.V & S.Q & G.L & M.Q & $\mathbf{F}_{\text {calc }}$ & $\mathbf{F}_{\text {tab }}$ \\
\hline Regressão & 0,999 & 5 & 0,199 & 20,98 & 5,05 \\
Resíduo & 0,048 & 5 & 0,009 & & \\
Total & 1,046 & 10 & & & \\
\hline
\end{tabular}

$F . V$ = fonte de variação; $S . Q$ = soma quadrática; $G . L$ = graus de liberdade; $M . Q$ = média quadrática; Coeficiente de determinação $R^{2}=0,9545 ; \%$ de variância explicada $=95,45 \%$.
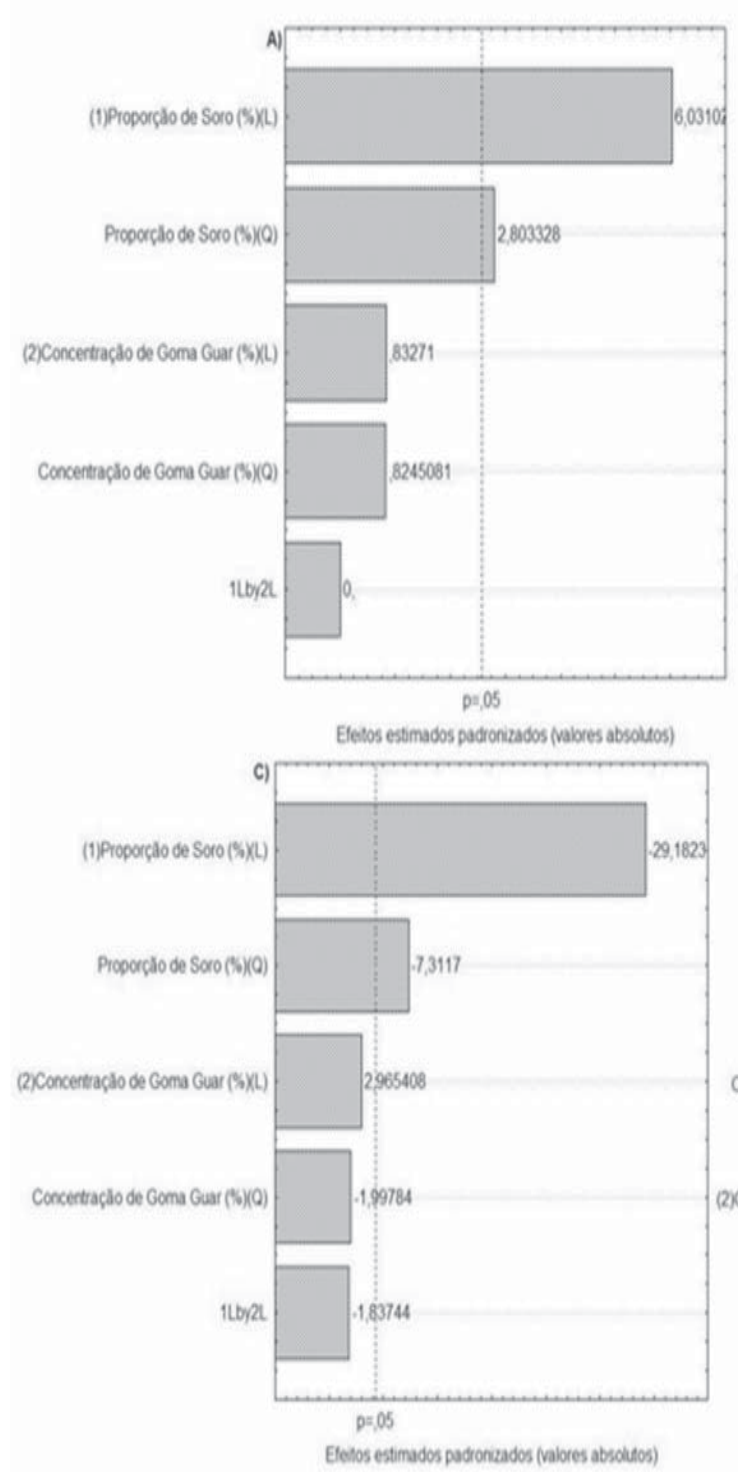
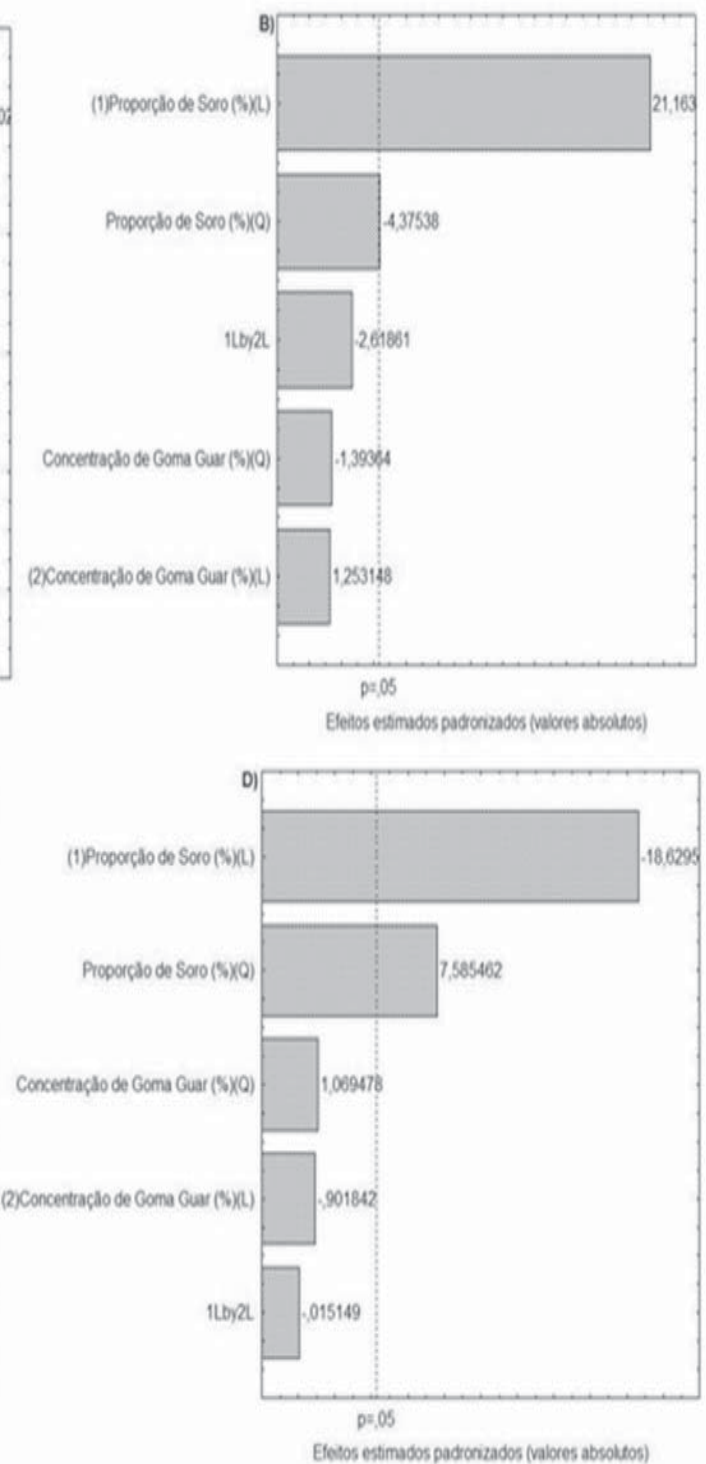

FIGURA 1 - EFEITOS ESTIMADOS PARA AS RESPOSTAS: TEMPO DE FERMENTAÇÃO (a), LACTOSE (B), SÓLIDOS TOTAIS (C) E ACIDEZ TITULÁVEL (D) 
O modelo estatístico para o teor de lactose está representado pela equação 1 , utilizada para gerar a superfície de resposta apresentada na Figura 2.

$$
\text { Lactose }=5,15+0,343 \text { (P.S.) }-0,084 \text { (P.S.) })^{2}
$$

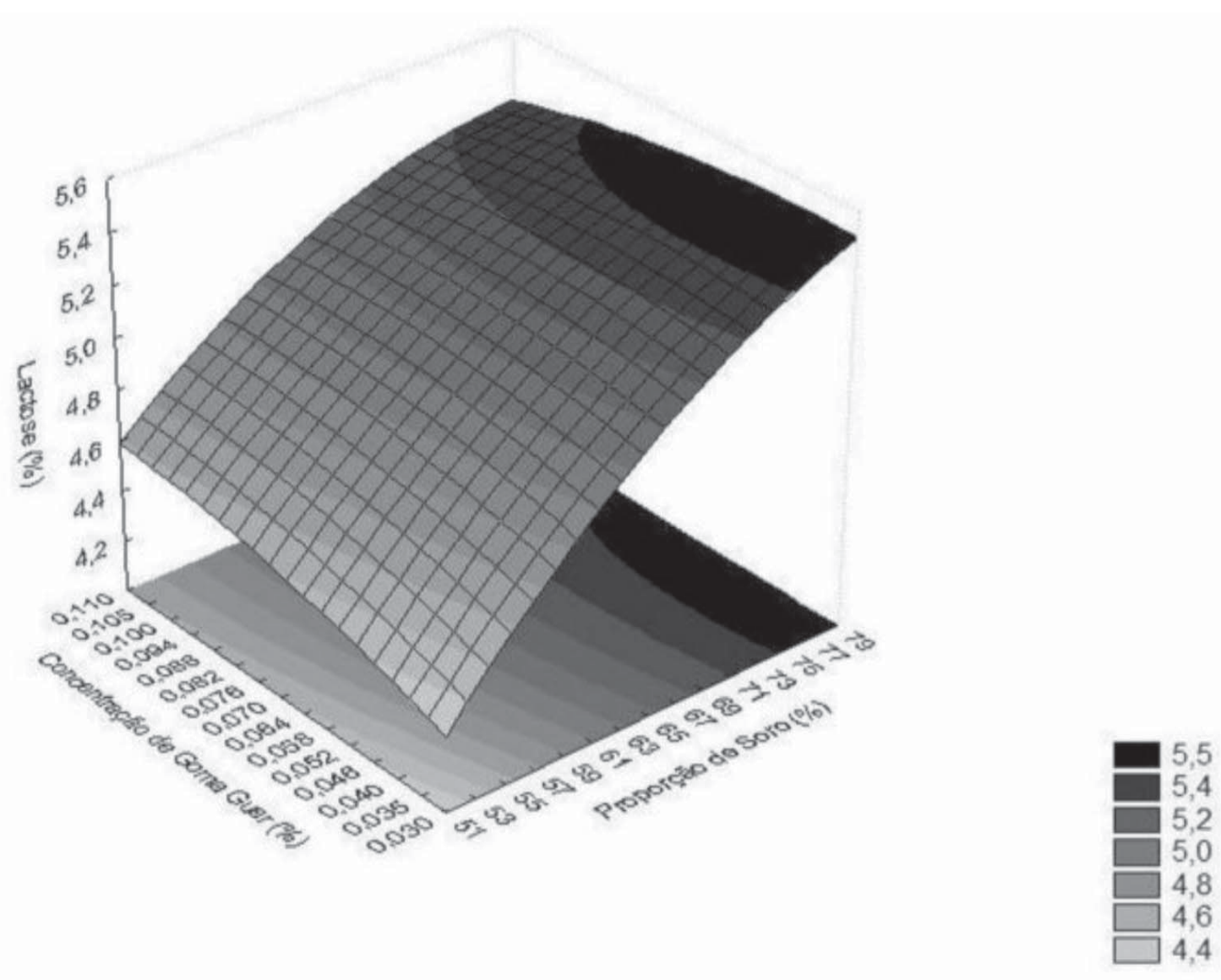

\section{FIGURA 2 - SUPERFÍCIE DE RESPOSTA QUE DESCREVE A INFLUÊNCIA DA PROPORÇÃO DE SORO E DE HIDROCOLOIDE SOBRE A LACTOSE DAS BEBIDAS LÁCTEAS}

A superfície de resposta para a lactose (Figura 2) mostra que bebidas preparadas com maiores proporções de soro apresentaram teor de lactose mais elevado ao final da fermentação. A fermentação do tipo láctica tem a lactose como principal substrato que é convertida em ácido láctico. Somente $20 \%$ do substrato sofre a conversão, mas é o suficiente para produzir a coagulação das proteínas pela diminuição do pH até o ponto isoelétrico das caseínas (AMIOT, 1991).

O metabolismo dos componentes do leite é incompleto na fermentação láctica, ocorrendo pré-digestão considerada benéfica devido à produção de compostos intermediários (como o ácido láctico e outros ácidos orgânicos), além de outros compostos orgânicos capazes de controlar o crescimento de vários micro-organismos e de regular a flora intestinal do consumidor (SABOYA, 1997). O abaixamento do $\mathrm{pH}$ em todos os produtos de leites fermentados não somente retarda o crescimento de micro-organismos indesejáveis no produto, mas também proporciona sabor agradável e melhor conservação das suas propriedades.

A Tabela 7 apresenta a análise de variância da variável resposta teor de sólidos totais. 
TABELA 7 - ANOVA PARA OS TEORES DOS SÓLIDOS DO PRODUTO DA FERMENTAÇÃO

\begin{tabular}{cccccc}
\hline F.V & S.Q & G.L & M.Q & $\mathbf{F}_{\text {calc }}$ & $\mathbf{F}_{\text {tab }}$ \\
\hline Regressão & 19,079044 & 5 & 3,81581 & 28,31 & 5,05 \\
Resíduos & 0,673846 & 5 & 0,1348 & & \\
Total & 19,75289 & 10 & $-\cdots$ & & \\
\hline
\end{tabular}

F.V = fonte de variação; $S . Q$ = soma quadrática; $G . L$ = graus de liberdade; $M . Q$ = média quadrática; Coeficiente de determinação $R^{2}=0,9656 ; \%$ de variância explicada $=96,56 \%$.

A ANOVA dos resultados obtidos para os teores de sólidos totais (Tabela 7) apresentou coeficiente de determinação $\left(R^{2}\right)$ de 0,9656 e valor de $F_{\text {cal, }}, 5,6$ vezes superior ao valor de $F_{\text {tabç }}$. Esses dados geram modelo codificado estatisticamente preditivo e significativo, equação 2, podendo-se verificar a superfície de resposta na Figura 3.

$$
\text { Sólidos totais }=11,84-1,488 \text { (P.S.) }-0,444 \text { (P.S.) })^{2}
$$

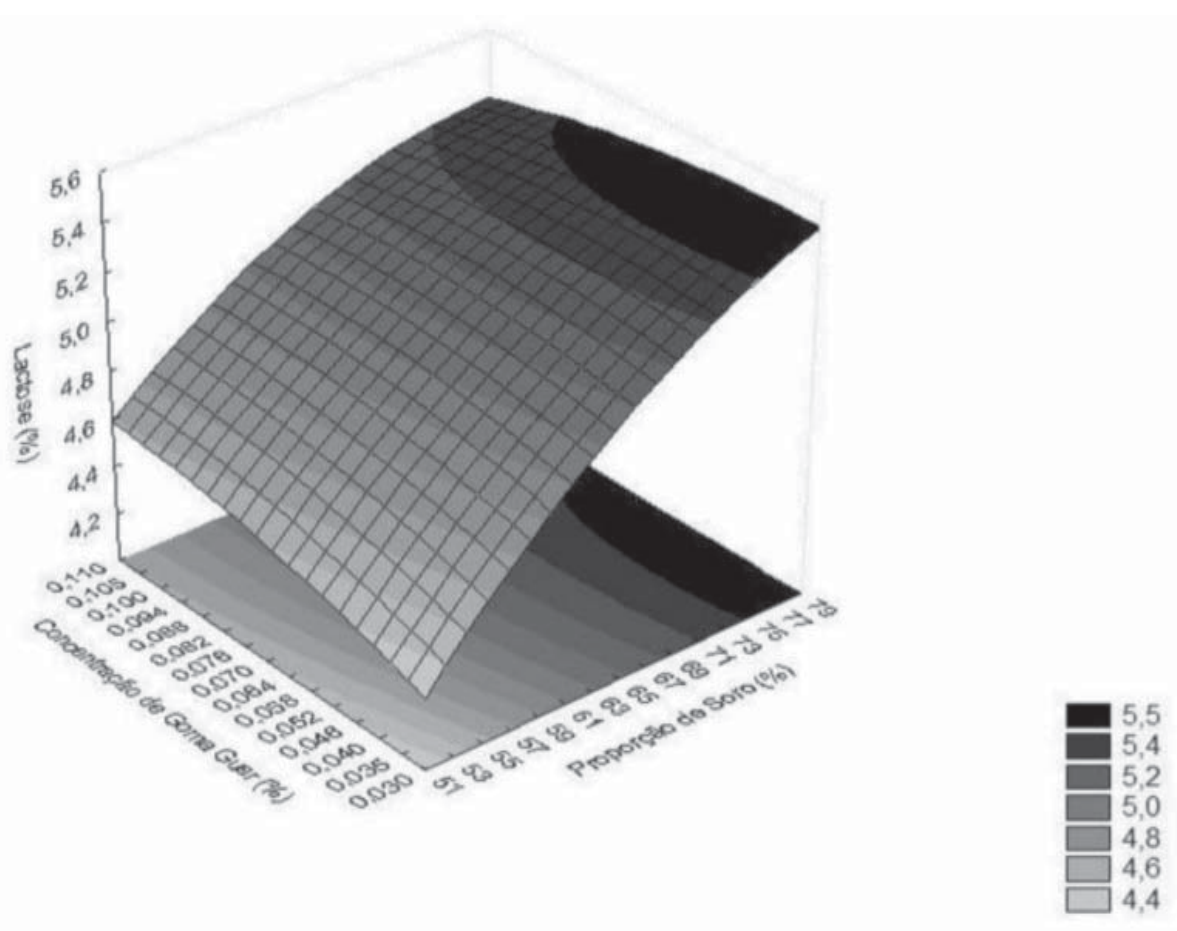

\section{FIGURA 3 - SUPERFÍCIE DE RESPOSTA QUE DESCREVE A INFLUÊNCIA DA PROPORÇÃO DE SORO E DE HIDROCOLOIDE SOBRE OS SÓLIDOS TOTAIS DA BEBIDA LÁCTEA}

Pode-se constatar pela Figura 3 que o teor de sólidos totais é inversamente proporcional à percentagem de soro, ou seja bebidas elaboradas com maior porcentagem de soro apresentam menores teores de sólidos totais. Resultado similar foi observado por Cunha et al. (2008) avaliando bebida láctea e leite fermentado adicionados de probióticos. Como o teor de sólidos totais influi na viscosidade dos produtos torna-se necessário ajustá-lo para se obter a viscosidade desejada (MARTÍN-DIANA et al., 2003).

A Tabela 8 apresenta a análise de variância da variável resposta acidez titulável. 
TABELA 8 - ANOVA DOS RESULTADOS DA ACIDEZ TITULÁVEL DAS BEBIDAS
LÁCTEAS FERMENTADAS

\begin{tabular}{cccccc}
\hline F.V & S.Q & G.L & M.Q & $\mathbf{F}_{\text {calc }}$ & $\mathbf{F}_{\text {tab }}$ \\
\hline Regressão & 44,324 & 5 & 8,865 & 27,95 & 5,05 \\
Resíduos & 1,586 & 5 & 0,317 & & \\
Total & 45,910 & 10 & & & \\
\hline
\end{tabular}

$F . V$ = fonte de variação; $S . Q$ = soma quadrática; $G . L$ = graus de liberdade; $M . Q$ = média quadrática; Coeficiente de determinação $R^{2}=0,9654 ; \%$ de variância explicada $=96,54 \%$.

A análise de variância dos resultados da acidez titulável (Tabela 8) apresentou valor de $F_{\text {calc }}$ de 27,95 , muito significativo, e porcentagem de variação explicada $\left(R^{2}\right)$ pelo modelo de $96,54 \%$, indicando bom ajuste dos dados a esse modelo (equação 3 ) e permitindo a geração de superfície de resposta (Figura 4).

$$
\text { Acidez titulável }=49,36-2,174 \text { (P.S.) + 1,054 (P.S.) })^{2}
$$
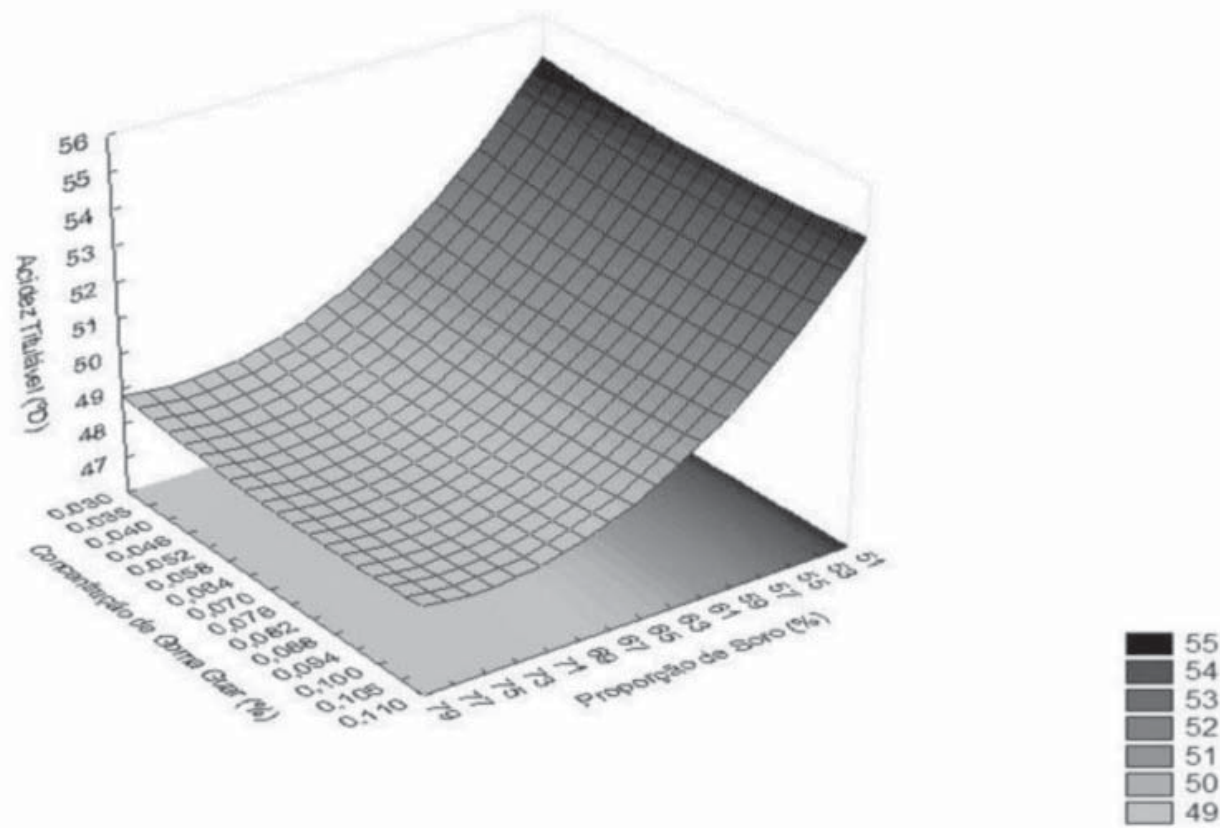

\section{FIGURA 4 - SUPERFÍCIE DE RESPOSTA QUE DESCREVE A INFLUÊNCIA DA PROPORÇÃO DE SORO E DE HIDROCOLOIDE SOBRE A}

\section{ACIDEZ TITULÁVEL DA BEBIDA LÁCTEA}

Verifica-se pela Figura 4 que a porcentagem de soro é inversamente proporcional à acidez titulável das bebidas lácteas em razão dos micro-organismos responsáveis pela fermentação serem beneficiados pelos nutrientes do leite, os quais inexistem no soro ou estão em menor concentração. Pinto et al. (2005) observaram que bebidas lácteas fermentadas elaboradas com $65 \%$ de soro e $0,03 \%$ de goma guar apresentaram baixa acidez e destacaram a preferência dos consumidores por bebidas lácteas fermentadas menos ácidas. 


\section{CONCLUSÃO}

A percentagem de soro influenciou significativamente $(p<0,05)$ o tempo de fermentação, os teores de lactose, sólidos totais e a acidez titulável das bebidas lácteas fermentadas. Já a concentração de hidrocoloide não exerceu influência significativa nas variáveis estudadas.

As bebidas lácteas preparadas com maior porcentagem de soro tendem a apresentar maior teor de lactose, e menores teores de sólidos totais e acidez titulável. Nessas condições é possível elaborar bebidas lácteas fermentadas com menor porcentagem de soro (65\%), de goma guar $(0,03 \%)$ e menor tempo de fermentação, condição que pode ser atrativa na utilização de soro do leite.

\section{ABSTRACT \\ EFFECT OF WHEY AND GUAR GUM IN THE LEVELS OF LACTOSE, LACTIC ACID AND FERMENTATION TIME OF MILK BEVERAGE}

The main objective of this work was to study the effect of percentages of whey and hydrocolloid (guar gum) in the amounts of lactose, lactic acid and fermentation time for milk beverages using a central composite rotational experimental design (DCCR), with three central points, totaling 11 experiments. Were utilized percentages of whey/milk of $51,55,65,75$ and $79 \%$; and hydrocolloid percentage at $0.03,0.04,0.07,0.10$ and $0.11 \%$. Experimental data were analyzed by ANOVA with a significance level of $5 \%$. The percentage of whey has influenced significantly $(p<0.05)$ the time of fermentation, the lactose content, the percentage of total solids and acidity, but the percentage of the hydrocolloid had no significant influence $(p<0.05)$ in the same characteristics of the fermented milk beverage. Lower fermentation times were achieved when using maximum $65 \%$ whey. The greatest concentration of lactose in the experiments were obtained with the highest percentage of the whey, while beverages with lower whey had higher percentage of total solids and acidity.

KEY-WORDS: DAIRY BEVERAGES; MILK WHEY; HYDROCOLLOIDS.

\section{REFERÊNCIAS}

1 ALMEIDA, K.; BONASSI, I.; ROÇA, R. Características físicas e químicas de bebidas lácteas fermentadas e preparadas com soro de queijo minas frescal. Ciência e Tecnologia de Alimentos, v. 21, n. 2, p. 187-192, 2001.

2 AMIOT, J. Ciência y tecnologia de la leche. Zaragoza: Acribia, 1991. 547 p.

3 ANDRADE, R.; MARTINS, J. Influência da adição da fécula de batata-doce (Ipomoea batatas L.) sobre a viscosidade do permeado de soro de queijo. Ciência e Tecnologia de Alimentos, Campinas, v. 22, n. 3, p. 249-253, 2002.

4 Association of Official Analytical Chemists (AOAC). Official methods of analysis of AOAC International. $17^{\text {th }}$ ed. Washington, 2000. 1094 p.

5 BARROS NETO, B.; SCARMINIO, I. S.; BRUNS, R. E. Como fazer experimentos. Porto Alegre: Bookman, 2010. $413 \mathrm{p}$.

6 BICUDO, M.O.P.; VASQUES, E.C.; ZUIM, D.R.; CANDIDO, L.M.B. Elaboração e caracterização de bebida fermentada à base de extrato hidrossolúvel de quinoa com polpa de frutas. Boletim do CEPPA, Curitiba, v. 30, n. 1, p. 19-26, 2012.

7 BRASIL. Ministério da Agricultura, Pecuária e Abastecimento. Instrução Normativa $\mathrm{n}^{\circ} 51$, de 18 de setembro de 2002. Aprova os regulamentos técnicos de produção, identidade e qualidade do leite tipo A, do leite tipo $\mathrm{B}$, do leite tipo $\mathrm{C}$, do leite pasteurizado e do leite cru refrigerado e o regulamento técnico da coleta de leite cru refrigerado e seu transporte a granel. Diário Oficial [da] República Federativa do Brasil, Poder Executivo, Brasília, DF, 20 set. 2002. Seção 1, p.13.

8 BRASIL. Ministério da Agricultura, Pecuária e Abastecimento. Instrução Normativa n 68, de 12 de dezembro de 2006. Oficializa os métodos analíticos físico-químicos para controle de leite e produtos lácteos, determinando que sejam utilizados nos laboratórios nacionais agropecuários. Diário Oficial [da] República Federativa do Brasil, Poder Executivo, Brasília, DF, 14 dez. 2006. Seção 1, p.8. 
9 CUNHA, T.M.; CASTRO, F.P.; BARRETO, P.L.M.; BENEDET, H.D.; PRUDENCIO, E.S. Avaliação físicoquímica, microbiológica e reológica de bebida láctea e leite fermentado adicionados de probióticos. Semina: Ciências Agrárias, Londrina, v. 29, n. 1, p. 103-116, 2008.

10 DICKINSON, E. Hydrocolloids at interfaces and the influence on the properties of dispersed systems. Food Hydrocolloids, v. 17, p. 25-39, 2003.

11 DICKINSON, E. Hydrocolloids as emulsifiers and emulsion stabilizers. Food Hydrocolloids, v. 23, p. 14731482, 2009

12 FERREIRA, S.P.; PINTO, M.H.; SANTOS, P.P.; VARELA, W.J.; RUIZ, W.A.; AUGUSTO, M.M.M. Efeito da proporção de soro e da concentração de hidrocolóide no tempo de fermentação e extrato seco de bebidas lácteas. In: CONGRESSO REGIONAL DE INICIAÇÃO CIENTÍFICA E TECNOLÓGICA EM ENGENHARIA, 20., 2005, Foz do Iguaçu. Resumos... Foz do Iguaçu: UNIOESTE, 2005. p. 375.

13 GARCIA-CRUZ, C.H. Uso de hidrocolóides em alimentos: revisão. Higiene Alimentar, São Paulo, v. 15, n. 87, p. 19-29, 2001.

14 MARTÍN-DIANA, A.B.; JANER, C.; PELÁEZ, C.; REQUENA, T. Development of a fermented goat's milk containing probiotic bacteria. International Dairy Journal, Barking, v. 13, n. 10, p. 827-833, 2003.

15 MARTINIS, E.C.P.; ALVES, V.F.; FRANCO, B.D.G.M. Bioconservação de alimentos. Biotecnologia Ciência \& Desenvolvimento, n. 29, p. 114-119, 2002.

16 MUNHOZ, M.P.; WEBER, F.H.; CHANG, Y.K. Influência de hidrocolóides na textura de gel de amido de milho. Ciência e Tecnologia de Alimentos, Campinas, v. 24, n. 3, p. 403-406, 2004.

17 PELEGRINE, D.H.G.; CARRASQUEIRA, R.L. Aproveitamento do soro do leite no enriquecimento nutricional de bebidas. Brazilian Journal of Food Technology, VII BMCFB, p. 145-151, 2008.

18 PINTO, M.H.; SANTOS, P.P.; FERREIRA, S.P.; VARELA, W.J.; RUIZ, W.A.; AUGUSTO, M.M.M. Verificação da aceitação por consumidores de uma bebida láctea fermentada visando a máxima utilização do soro de leite. In: MOSTRA DA PRODUÇÃO UNIVERSITÁRIA, 4., 2005, Rio Grande. Resumos...Rio Grande: FURG, 2005.

19 PORTO, L.M.; SANTOS, R.C.; MIRANDA, T.L.S. Determinação das melhores condições operacionais do processo de produção de ricota. Boletim do CEPPA, Curitiba, v. 23, n. 1, p. 173-182, 2005.

20 SABOYA, L.V.; OETTERER, M.; OLIVEIRA, A.J. Propriedades profiláticas e terapêuticas de leites fermentados - uma revisão. Boletim da Sociedade Brasileira de Ciência e Tecnologia de Alimentos, v. 31, n. 2, p. 176-185, 1997.

21 SALADO, G.A.; ANDRADE, M.O. Processamento e qualidade nutricional do iogurte. Boletim Cultural, Bauru, v. 7, p. 1-35, 1989.

22 SILVA, K.; BOLINI, H.M.A.; ANTUNES, A.J. Soro de leite bovino em sorvete. Alimentos e Nutrição, Araraquara, v. 15, n. 2, p. 187-196, 2004.

23 SIKORA, M.; BADRIE, N.; DEISINGH, A.K.; KOWALSKI, S. Sauces and dressings: a review of properties and applications. Critical Reviews in Food Science and Nutrition, v. 48, n. 1, p. 50-77, 2008.

24 SIVIERI, K.; OLIVEIRA, M.N. Avaliação da vida-de-prateleira de bebidas lácteas preparadas com fat replacers (Litesse e Dairy-lo). Ciência e Tecnologia de Alimentos, Campinas, v. 22, n. 1, p. 24-31, 2002.

25 SPADOTI, L.; DORNELLAS, J.; PETENATE, A.; ROIG, S. Avaliação do rendimento do queijo tipo prato obtido por modificações no processo tradicional de fabricação. Ciência e Tecnologia de Alimentos, Campinas, v. 23, n. 3, p. 493-499, 2003.

26 SMITH, L. Overtraining, excessive exercise and altered immunity: is this a T helper-1 versus T helper-2 lymphocyte response? Sports Medicine, Texas, v. 33, n. 5, p. 347-364, 2003.

27 SPREER, E. Lactologia industrial. Zaragoza: Acribia, 1991. 617 p. 
28 STATSOFT INC. Statistica data analysis system. Version 5.0. Tulsa, 1995.

29 TAN, C.T. Beverage emulsions. In: FRIBERG, S.E.; LARSSON, K.; SJOBLOM, J. Food emulsions. New York: Marcel Dekker, 2004. p. 485-524. 